\title{
Investigation of Nonlinear Behaviour of Semiburied Cylindrical Concrete Reservoir without Dynamic Load Effect
}

\author{
Mazhar Fatahi $\mathbb{D}^{1},{ }^{1}$ Mahdi Meftah Halghi, ${ }^{2}$ and Mehran Soltani Tehrani ${ }^{3}$ \\ ${ }^{1}$ Department of Civil Engineering, Loghman Hakim Golestan Non-Profit Institute, Agh-Ghala, Iran \\ ${ }^{2}$ Department of Civil Engineering, Faculty of Water Engineering, \\ Gorgan University of Natural Resources and Agricultural Sciences, Gorgan, Iran \\ ${ }^{3}$ Department of Civil Engineering, Najafabad Branch, Islamic Azad University, Najafabad, Iran \\ Correspondence should be addressed to Mazhar Fatahi; mazharfatahi@gmail.com
}

Received 3 November 2020; Revised 14 November 2020; Accepted 24 December 2020; Published 16 January 2021

Academic Editor: Seyed Mahdi Seyed Kolbadi

Copyright (c) 2021 Mazhar Fatahi et al. This is an open access article distributed under the Creative Commons Attribution License, which permits unrestricted use, distribution, and reproduction in any medium, provided the original work is properly cited.

\begin{abstract}
This study aimed to examine the effect of rigid and flexible foundations on the response by a semiburied water storage reservoir. In this study, the reservoir support conditions of both flexible and inflexible states were studied. The seismic behaviour of reinforced and prestressed concrete reservoirs was compared based on their support conditions. The powerful numerical method FEM was used to study about the nonlinear behaviour of cylindrical reservoirs using static and dynamic nonlinear analysis. The values of the results correcting factor in the design codes and standards were evaluated. Moreover, the response correcting behaviour (R) was evaluated based on the findings from a push-over and nonlinear dynamic analysis. This research finding indicated that the reservoir shapes and support types affect the deformability of the reservoirs. Reservoirs with prestressed concrete show less flexibility compared to reinforced concrete reservoir. Finally, it is resulted that displacement, base shear, and wave height obtained from time history analysis are more than those of response spectrum analysis, indicating insufficiency of response spectrum analysis.
\end{abstract}

\section{Introduction}

Fluid and gas storage tanks are very important. Today, the efficiency of such structures in many industries is undeniable. The main application of these tanks is in industry and for purposes such as water storage and storage. They are usually made of steel or reinforced concrete, and in terms of shape, they are usually made of cubes or cylinders. Conventional reinforced concrete reservoirs have been widely used for urban and industrial equipment for decades [1]. Different configuration of storage reservoirs is going to be built based on the structure shape, building materials, support conditions, and so on. Buried reservoirs are categorized based on the reservoir shapes, the boundary condition, the support types, and the construction material. Many reservoirs, especially cylindrical ones, are made of steel because of their chemical resistance and mechanical strength. The concrete reservoir may envisage a radical transformation of the conception of technology in the context of the worldwide request of shaping the fourth industrial revolution [2]. This is because of the improved durability compared with the numerous failures observed in steel reservoirs during the past earthquakes.

The number of water storage tanks and its importance is increasing over time. Therefore, it is necessary to carefully study the behavior of this type of structure. In this regard, phenomena such as earthquakes and explosions should also be applied to these structures [3]. The next important goal of such studies, after a proper understanding of the behaviour of these structures, is to identify optimal methods to increase their resistance to these phenomena to reduce damage [4]. Although some studies have been performed on the nonlinear response of reservoirs underground tremors, still the need to study the nonlinear response and the degree of deformability of semiburied cylindrical concrete reservoir are strongly felt. The response factor is a term usually used in 
chromatography and spectroscopy useful for the calculation of quantitative responses in detectors that correlate to amounts of investigated analyses [5]. Also, Adom-Asamoah evaluates the structural characteristics of deep beams made from reinforced palm kernel shell concrete (PKSC) and normal weight concrete (NWC) [6].

\section{Materials and Methods}

2.1. Existing Regulations and Standards for Liquid Reservoirs. In this section, a brief overview of existing regulations and documents for earthquake-resistant guideline of liquid containers is provided. In the Eulerian and Lagrangian methods, the governing fluid structure system equation is calculated using wave propagation through the fluid by assuming linear compressibility and in-viscousity [5]. This review focuses on regulations and standards recently used worldwide. The International Building Code (IBC 2011) is one of the widely used regulations which provides a diverse and detailed technique for calculating dynamic forces on liquid reservoirs but it is more commonly used in the United States. ASCE Standard 7-10 2010 is used for seismic design of conventional liquid storage reservoirs. In this standard, ground motion is defined as the maximum earthquake response spectrum (MCE), with a $2 \%$ probability that a more severe earthquake may occur over each half-century period [7].

There are currently no direct guidelines for the design of environmental structures in Canadian design regulations and standards. The ACI 350.3-06 Standard can be considered as the most referential document in this field. The ACI 350 based on the ultimate strength design method, which is based on the Hassner (1963) technique, is considered, and the resulting seismic forces are calculated. The continuity condition of contained fluid in this theory consisted of boundary conditions of the contact interface between tank body and fluid as well as fluid-free surface. The fluid is assumed to be irrotational, incompressible, and inviscid and also there is no mean flow of the fluid. Furthermore, the linear theory of sloshing is utilized for the convective response of the contained liquid in the tank. The velocity of pressure wave is assumed to be infinite in the small volume of containers.

2.2. Seismic Design of Concrete LCs. According to ACI 350.3 (2001 and 2006), all structural parts of liquid container body must be designed to withstand the effects of horizontal and vertical design acceleration in combination with the effects of applied static loads to provide a set of thorough and comprehensive procedures for the seismic analysis and design of all types of liquid-containing environmental concrete structures. Their committee's decision was influenced by the recognition that liquid-containing structures are unique structures whose seismic design is not adequately covered by the leading national codes and standards (ACI 350.3, 2006) [8].

When liquid containers are subjected to seismic loading caused by earthquake, the reflection can be illustrated by two main vibration modes which vary based on phenomena such as wall flexibility and rigidity at the base and level of fluctuation. The first vibration mode is impulsive that is combined with the lower portion of the liquid and can be considered with added mass method and even more recent technique. It should be noted that the second part is convective and is related to the upper part of the fluid in the tank [9].

\section{Results and Discussion}

3.1. Finite Element Method. In real conditions, the distribution of seismic forces around a circular reservoir is in accordance with Figure 1 and in the form of a cosine distribution. In this study, the use of axially symmetric elements in finite element analysis of circular reservoirs is investigated. Axial symmetry elements are much easier to use than shell elements. The abovementioned evaluation is the most direct method to study the sensitivity of geotechnical parameters, but it is only suitable to study the single-parameter sensitivity problem. However, in applying these elements, the cosine distribution for hydrodynamic forces cannot be used, so the linear pressure distribution must be considered in all around the circular-cross section of the tank. FEM for the correct investigation of the application of the uniform distribution of all-round pressure considering the maximum pressure is shown in Figure 1 [10].

For this purpose, shell elements have been used to model the fluid storage tank wall. This type of element has the ability to model the desired pressure distribution, interaction definition, and other numerical calculations. In order to check the accuracy of the hypotheses made in this section, modelling and numerical analysis are performed by all the mentioned methods and finally the results are compared with each other.

3.2. Numerical Simulations. In this software, a computer model can be created using graphic and interactive techniques. To simplify the problem, this paper only considers one tank and its foundation. The LC is modelled using 3D shell elements and axial symmetric boundary conditioning. Since the properties of materials in this study are assumed to be linear, after static analysis, it has been used to simulate the behaviour of this structure [11].

In this study, three finite element models are used. Full reservoir model (FT): in this case, the reservoir is completely modelled using 1680 square elements of four nodes, with dimensions of 0.9 by 0.9 meters; the name "full reservoir (FT)" is chosen for Figure 2(a). Half reservoir model (1/2T): in this case, half of the reservoir is modelled using 840 square shell elements with a diameter of 0.9 by 0.9 meters and is called the " $1 / 2 \mathrm{~T}$ " model (Figure 2(b)).

This model is used only for proper modelling research. Axial symmetric model (AXI): in this case, the whole reservoir is modelled using symmetric axial elements; it is called the model with 3 layers along high.

Finite element analysis is performed using ABAQUS software. Using the interaction and powerful simulation 


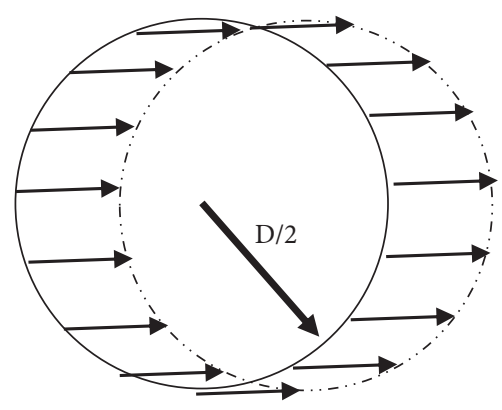

Actual distribution

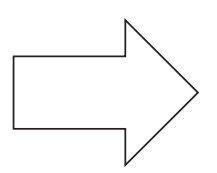

Figure 1: Actual and simplified hydrodynamic pressure distribution.

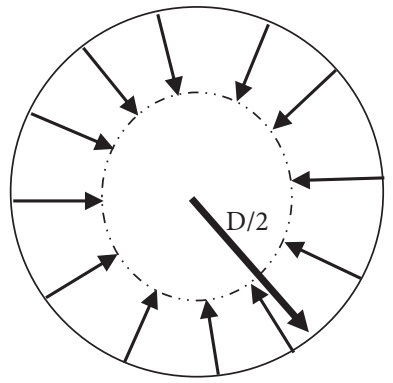

Simplified distribution

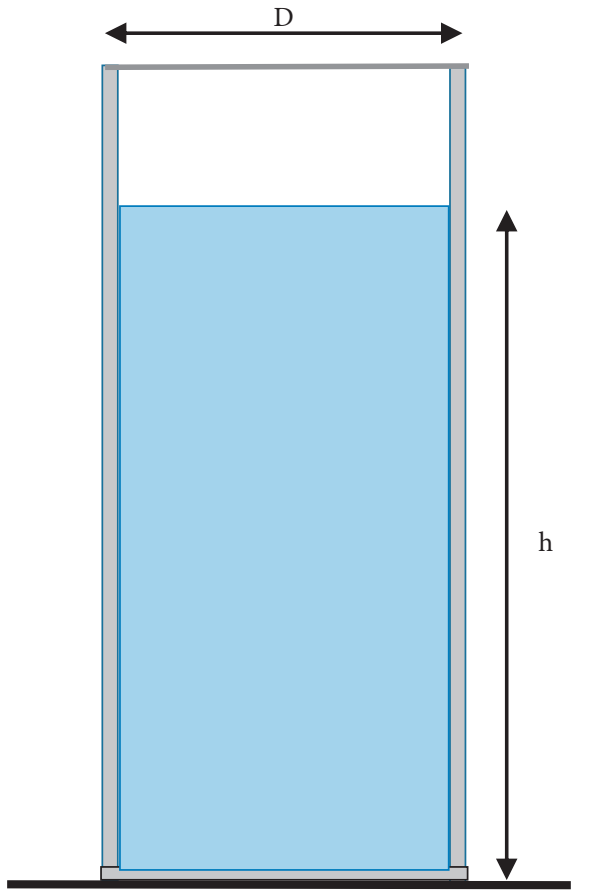

(a)

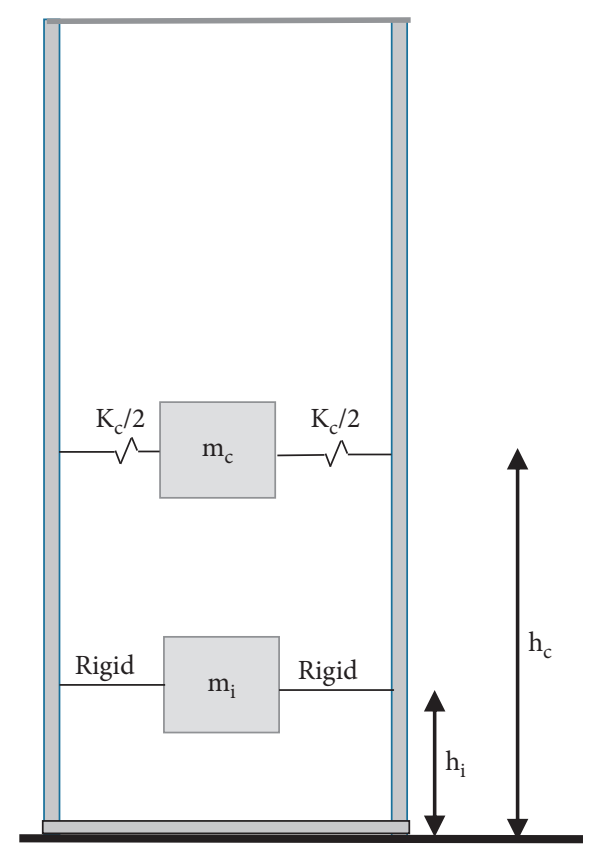

(b)

Figure 2: Circular reservoir finite element model: (a) full reservoir and (b) added mass and sloshing modelling.

technique of this software, the numerical model of the reservoir is designed. In this study, nonlinear dynamic analysis of time history is used in which the nonlinearity of building materials is considered $[12,13]$.

3.3. Problem Geometry. The reservoir is completely designed using quadrilateral shell elements, according to Figure 3 . The wall thickness is much less than the height of the wall and the diameter of the reservoir. Therefore, it is justified to consider shell elements in reservoir modelling. The shell elements used in this analysis have three degrees of freedom of movement and rotational in each node. In terms of water height, the reservoir wall is divided into equal elements of one meter, and in this networking, the number of elements along the wall to the water level for reservoir 1,2, and 3 are considered equal to 3,6 , and 9 , respectively. The length of the highest element for three reservoirs is equal to the free edge of the reservoir, i.e., $0.25,0.5$, and 0.6 meters, respectively. In order to maintain the proportion of the body in the unit value, around each reservoir is divided into 128 equal elements in which the size of each element on the peripheral circle of the reservoir is equal to 1 meter. As a result, the total number of elements for the three reservoirs will be 512, 896, and 1280 , respectively.

3.4. Research on the Correctness of the Model. To investigate the finite element model used in this study, finite element analysis was done for all different models with rigid bases using two finite element numerical programs SAP and ABAQUS. To do this, three different finite element models (out of six models) with fixed base conditions are considered. 

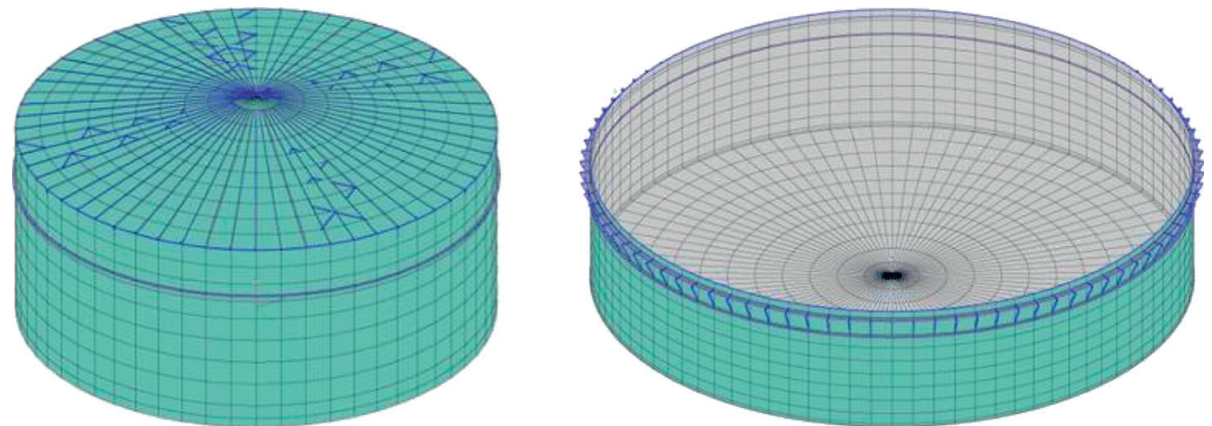

Figure 3: Finite element model for fluid reservoir, ABAQUS/CAE.

TABLE 1: Reactive force in the radial direction at the base of the reservoir under constant pressure.

\begin{tabular}{|c|c|c|}
\hline Reactive force $(\mathrm{kN} / \mathrm{m})$ & Reactive force $(\mathrm{kN} / \mathrm{m})$ & Reactive force $(\mathrm{kN} / \mathrm{m})$ \\
\hline
\end{tabular}

SAP full model ABAQUS full model SAP half model ABAQUS half model SAP axisymmetric model ABAQUS axisymmetric model 11.3 11.2 11.3

11.2 11.4 11.3

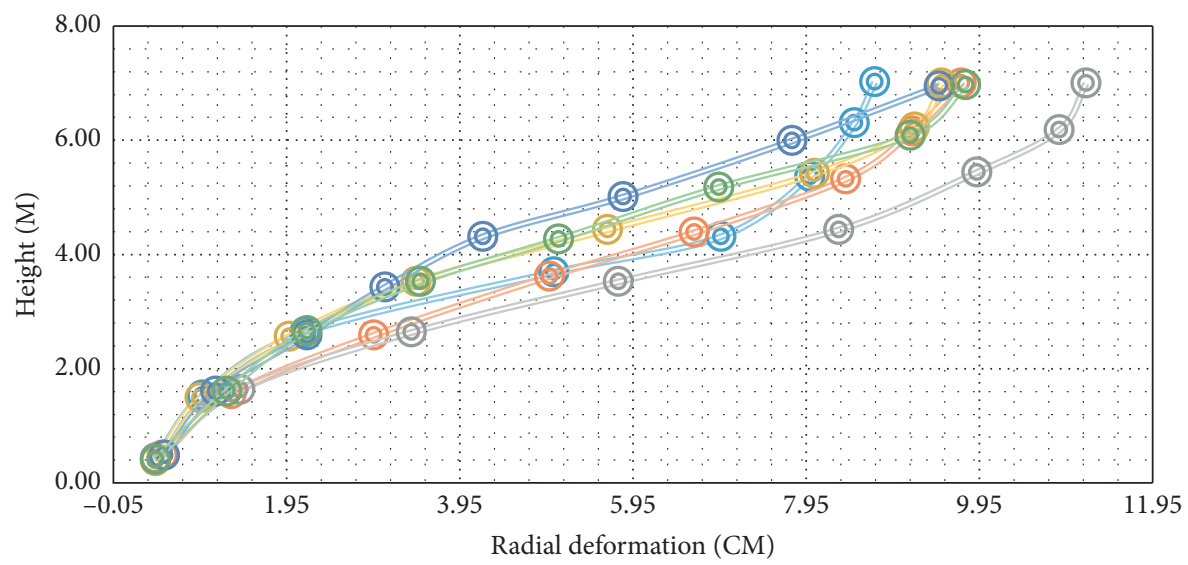

- - ABAQUS - symmetry

=- ABAQUS - half model

- - ABAQUS - full model

$$
\begin{aligned}
& =\text { - SAP - symmetry } \\
& =\text { - }=\text { SAP - half model } \\
& =\text { - }=\text { SAP - full model }
\end{aligned}
$$

FIgURE 4: Radial deformation under uniform pressure.

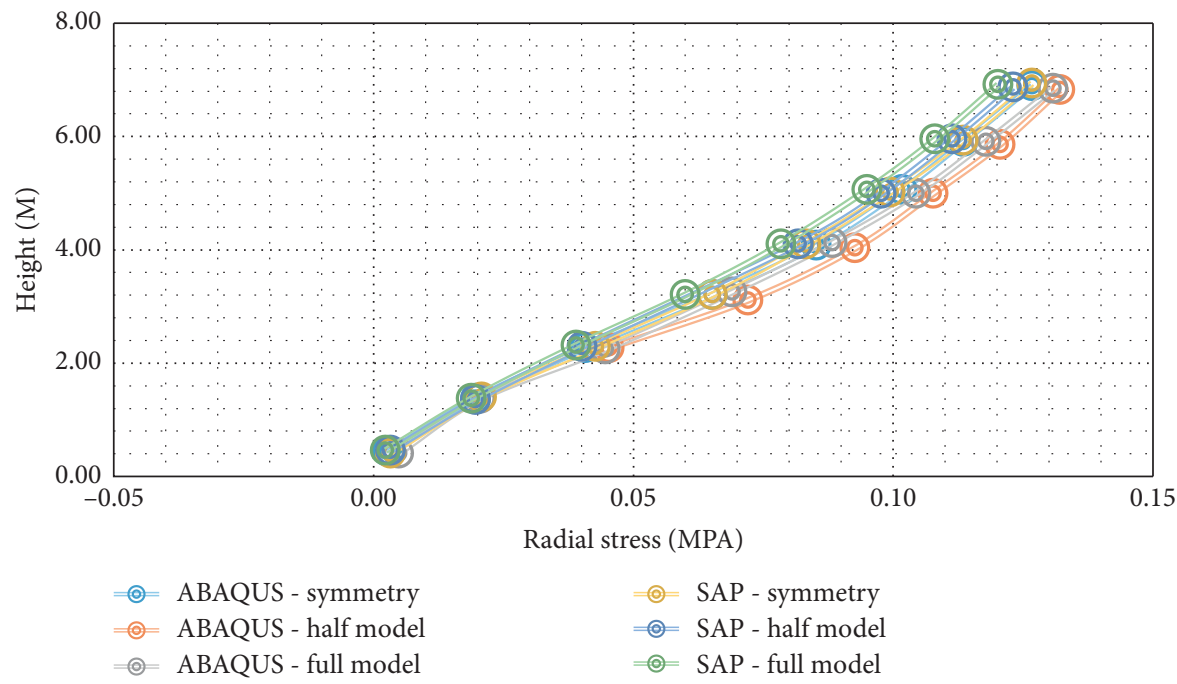

FIgURE 5: Environmental stress under uniform pressure. 


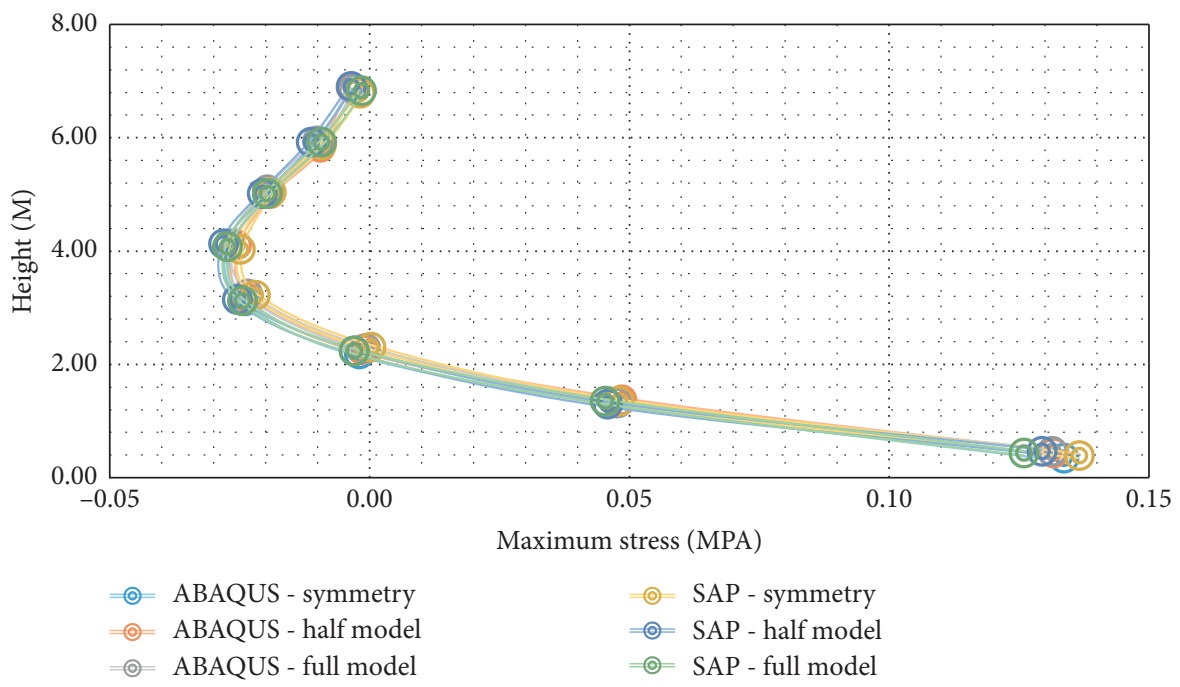

FIGURE 6: Maximum stresses in the vertical direction under uniform pressure.

Since the purpose of this study is to properly investigate the model selected for the reservoir using the ABAQUS program, a uniform pressure of $1.3 \mathrm{kPa}$ will be applied to the reservoir. As can be seen in Table 1, the reaction force in the radial direction at the base of the reservoir was very close to each other in all models and the maximum difference in results equal to $1.6 \%$ between the axisymmetric model and the full model is obtained, which indicates that the reservoir models considered using SAP and ABAQUS are compatible with each other.

As shown in Figure 4, the radial deformation in all FE models of reservoir wall heights is the same for models 1 and 2 in both programs. The maximum difference in radial wall deformation for models 1 and 2 in the two software programs is $7.6 \%$ at the top of the wall. This difference is inversely related to height. The average difference between the results for displacement is about $4 \%$, but the results are the same for the axial symmetric model 3 in ABAQUS and SAP.

Figure 5 shows the first principle stresses for all numerical models. The maximum difference between the first principle stresses in models 1 and 2 above the wall is equal to $7.6 \%$; the average difference is equal to $4 \%$. Similarly, the first principle stresses at different levels of height are obtained for models 1 and 2 in both computer programs.

Figure 6 shows that the second principle stresses in the vertical direction obtained almost identically for all $\mathrm{FE}$ models indicating the use of models 1,2 , or 3 in each of the two programs can arbitrarily give reliable results in finite element analysis for the considered parameters.

\section{Conclusion}

The presented problem turned out to be complex in numerical modelling. Moreover, the results did not lead to the real failure mode even though a range of external forces as well as material parameters were used. The complexity of geometry and considerable slenderness of structural elements with very different mechanical properties caused serious complications in stabilizing the algorithm of the applied FE software out of the real range of loads. Hence, the lower bound static estimation focused on the observed failure mode was used. It is suitable to use methods of uniform loads and symmetric axial elements in modelling the reservoir completely and obtaining its maximum response. In the usual method (based on regulations), the response of the reservoir is determined in terms of base shear and base torque more than the amount of analysis. The discrepancy in results is due to the effects of the concentration of impact and convective masses and other simplifying assumptions that are common in regulatory methods. The recommended Ri values for reinforced concrete reservoirs, with clamped and articulated bases, and preconcreted reservoirs with flexible braced bases are 2.5, 2.0, and 1.5 , respectively.

\section{Data Availability}

Requests for access to these data should be made to the corresponding author via the e-mail address: mazharfatahi@ gmail.com.

\section{Conflicts of Interest}

The authors declare that there are no conflicts of interest regarding the publication of this paper.

\section{References}

[1] S. M. S. Kolbadi, R. A. Alvand, and A. Mirzaei, "Three dimensional dynamic analysis of water storage tanks considering FSI using FEM," International Journal of Civil and Environmental Engineering, vol. 12, no. 3, pp. 377-386, 2018.

[2] C. Vargas-Elizondo, "On the role of ethics in shaping technology development," HighTech and Innovation Journal, vol. 1, no. 2, 2020.

[3] M. Barkhori, S. Maleki, M. Mirtaheri, M. Nazeryan, and S. M. S. Kolbadi, "Investigation of shear lag effect on tension members fillet-welded connections consisting of 
single and double channel sections," Structural Engineering and Mechanics, vol. 74, no. 3, pp. 445-455, 2020.

[4] S. M. S. Kolbadi, H. Davoodian, and S. M. S. Kolbadi, "Evaluation of nonlinear behavior of reinforced concrete Frames by explosive dynamic loading using finite element method," Civil Engineering Journal, vol. 3, no. 12, 1198 pages, 2017.

[5] A. Hafez, "Seismic response of ground-supported circular concrete tanks," Thesis, Ryerson University, Toronto, Canada, 2012.

[6] M. Adom-Asamoah, J. Banahene Osei, and K. AdinkraAppiah, "Structural characteristics of reinforced palm kernel shell concrete deep beams," Civil Engineering Journal, vol. 4, no. 7, 1477 pages, 2018.

[7] American Society of Civil Engineers (ASCE), "Structural Engineering Institute," Minimum Design Loads for Buildings and Other Structures, ASCE, Reston, VA, USA, 2005.

[8] ACI committee 2007, Report on Thermal and Volume Change Effects on Cracking of Mass Concrete (ACI207.2R-07), American Concrete Institute, Farmington Hills, MI. USA, 2007.

[9] P. Mortazavi, S. Bernard, J. Stephenson, B. W0haley, and J. Elliot, "seismic design of liquid retaining structures: a review of design methodologies and retrofit of a case study wwtp," in Proceedings of the 16th world conference on earthquake, 16WCEE, Santiago Chile, January 2017.

[10] CSA-A23.3, Design of Concrete Structures, Canadian Standards Association, Mississauga, Ontario, Canada, 2010.

[11] M. A. Haroun and G. W. Housner, "Earthquake response of deformable liquid storage tanks," Journal of Applied Mechanics, vol. 48, no. 2, pp. 411-418, 1981.

[12] C. A. Kircher, "Seismic regulations for passive structural control systems-overview of United States codes," in Proceedings of the Second World Conference, Wiley, Chichester, UK, December 1999.

[13] NZS3106, Code of Practice for Concrete Structures for the Storage of Liquids, Standards Association of New Zealand, Wellington, New Zealand, 2010. 